High spatial resolution readout of 3-D metabolic organ structure: an automated, lowtemperature redox ratio-scanning instrument.

Quistorff, Bjørn; C. Haselgrove, John; Chance, Britton

Published in:

Analytical Biochemistry

Publication date:

1985

Document version

Publisher's PDF, also known as Version of record

Citation for published version (APA):

Quistorff, B., C. Haselgrove, J., \& Chance, B. (1985). High spatial resolution readout of 3-D metabolic organ structure: an automated, low-temperature redox ratio-scanning instrument. Analytical Biochemistry, 148(2), 389400. 


\title{
High Spatial Resolution Readout of 3-D Metabolic Organ Structure: An Automated, Low-Temperature Redox Ratio-Scanning Instrument
}

\author{
BJøRn QuistorfF, ${ }^{*}$ John C. Haselgrove, and BritTon Chance
}

The Johnson Research Foundation, University of Pennsylvania, Philadelphia, Pennsylvania 19104, and

*Department of Biochemistry, Panum Institute, University of Copenhagen, Copenhagen 2200, Denmark

Received September 4, 1984

\begin{abstract}
Intraorgan compartmentation of metabolic processes plays an important role in the understanding of the physiological function of the integrated organ under normal as well as under pathological conditions. We describe here a technique by which 3-D information on tissue redox state may be obtained by means of automated scanning of surface fluorescence. The instrument allows for serial scanning of frozen tissue. A typical scan of a tissue volume of $3 \times 3 \times 2 \mathrm{~mm}$ at a linear resolution of $50 \mu \mathrm{m}$ and a spatial resolution of ca. $3 \times 10^{-7} \mathrm{ml}$ includes 144,000 single-point measurements of pyridine nucleotide and flavoprotein fluorescence within the tissue block. The scanning process is fully computerized and programs have been developed which allow 2- or 3-D reconstruction of the data in terms of "redox ratio models," exemplified here by a 3-D model of a spreading depression wave in the cerebral cortex of a gerbil. (C) 1985 Academic Press, Inc.

KEY WORDS: fluorescence spectroscopy; instrumentation; organ perfusion; mitochondria; flavoproteins; pyridine nucleotides; bioenergetics.
\end{abstract}

Carl Cori introduced the concept intracellular compartmentation to describe a fundamental principle of heterogeneous internal distribution of components of the metabolic apparatus in living cells (1). This has proven very useful to the understanding of the interplay of metabolic processes in the cell. Equally important in the understanding of the function of the integrated organ is the interaction between cells at the capillary level. Especially concerning the liver, terms like organ compartmentation (2), intercellular compartmentation (3), or metabolic zonation (4) have analogically been suggested to describe heterogeneous distribution of metabolic activity at the capillary level in the integrated organ.

The study of intercellular compartmentation requires special techniques, capable of monitoring metabolic activity with a spatial resolution of the order of a $\mathrm{fcw}$ cells. In recent years a number of such techniques have been developed, for example, freezetrapping, combined with chemical analysis of microdissected samples (5); various autoradiographic techniques, in particular the 2deoxyglucose method as used in studies of brain metabolism (6); and special spectroscopic techniques (7), including the one described in the present paper (8). For the study of the liver a number of techniques have been specially developed, asuch as a microlightguide technique applied to perfused liver (9), a hepatocyte column technique (1), sophisticated use of forward and retrograde perfusion of the liver (11), and a recently developed digitonin-perfusion technique allowing controlled release of intracellular material from different microcirculatory zones of the liver (12) and isolation of periportal and perivenous hepatocytes (13). Finally, NMR, which is a truly nondestructive and noninvasive technique, shows promising prospects in terms of obtaining regional metabolic information by means of phosphorous imaging, which has recently been achieved in the brain in vivo (14). 

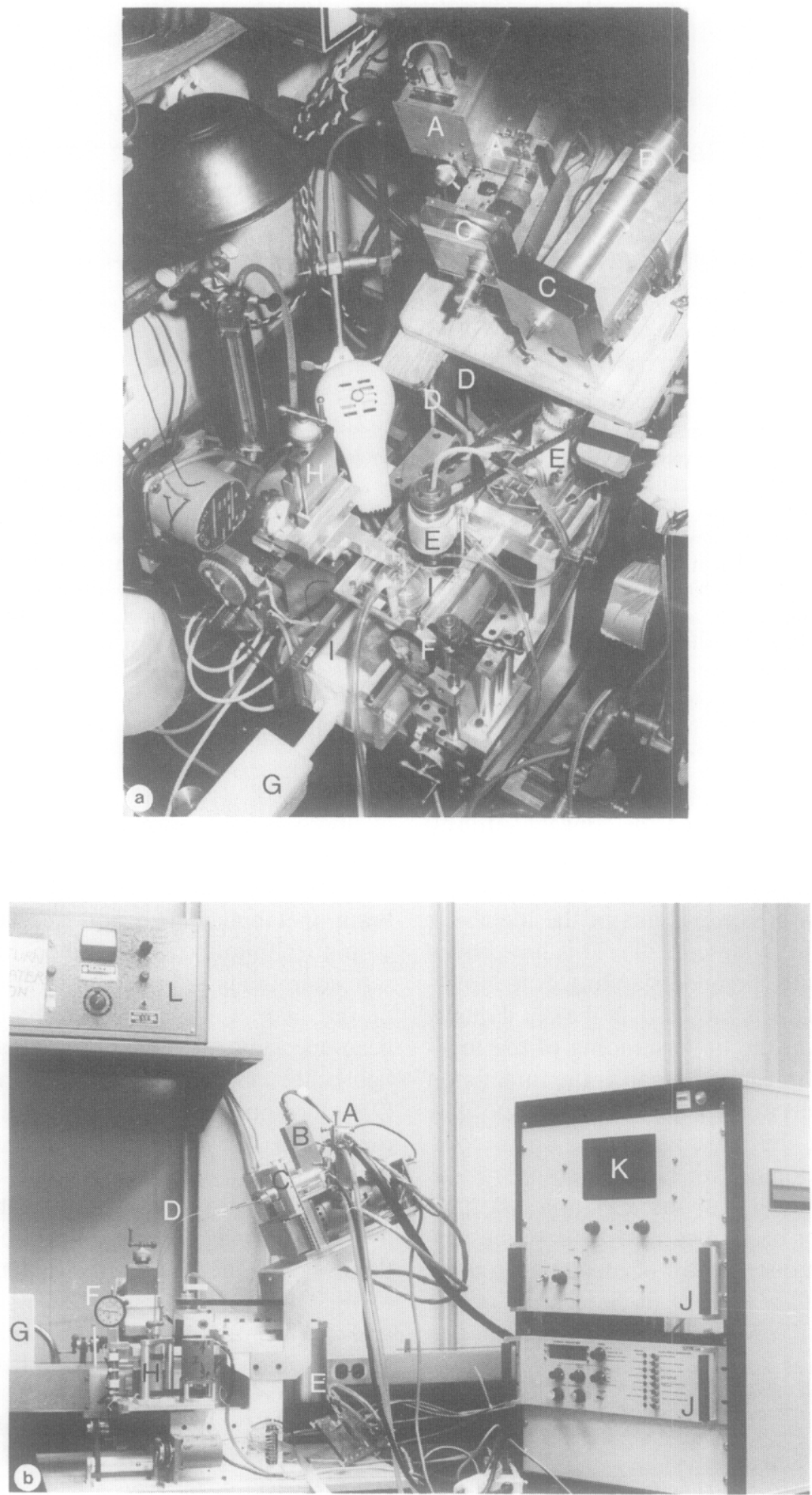
We describe here an optical redox ratioscanning technique, designed to study intercellular metabolic heterogeneity. The instrument operates on frozen tissue samples with a typical spatial resolution of ca. $3 \times 10^{-7}$ ml. Preliminary description of the instrument has appeared in relation to its use in different projects $(8,15-21)$. The present paper, however, aims at a complete description of the low-temperature scanning technique and its current use and potential in 2- or 3-dimensional metabolic studies in various tissues.

\section{MATERIALS AND METHODS}

\section{General Description of the Instrument}

The computer-operated scanning instrument is shown in Fig. 1. The original laboratory model on which the data presented here were recorded is shown in Fig. 1a, while Fig. Ib shows the most recent commercially available model. The technique is based on automated scanning of fluorescence and reflectance signals from the surface of frozen tissue via a microlightguide. The technique may also be used on nonfrozen samples, although for such applications the flying-spot scanner would usually be the instrument of choice (22).

Referring to the schematic drawing of Fig. 2, the instrument works, in short, as follows: The frozen sample, which may be obtained by a number of different feeeze-quenching techniques, is mechanically fixed in the scanning chamber of the instrument, partly submerged in liquid nitrogen. A flat surface is created by low-temperature milling (23). The microlightguide of the fluorometer, through which the optical signals are recorded, is

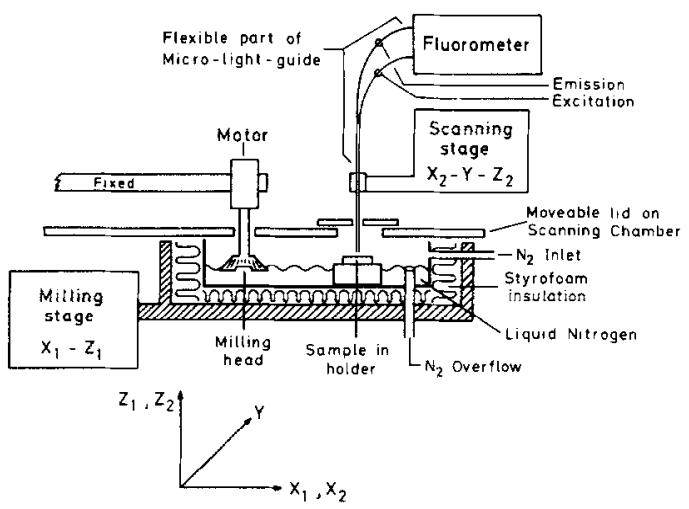

FiG. 2. Simplified diagram of low-temperature scanner. A flexible lightguide forms the optical coupling between the frozen sample and the fluorometer. Scanning is carried out by moving the tip of the microlightguide over the sample surface in the $X-Y$ plane ( $Y$ axis is normal to page), controlled by the scanning stage, $X_{2}-$ $Y-Z_{2}$. 3-D recordings are obtained by milling away layers of tissue parallel to the surface of the sample and repeating the scan on each new surface. Low-temperature milling is carried out by moving the entire low-temperature chamber with the sample (stage $X_{1}-Z_{1}$ ) relative to the rotating milling head.

placed over an appropriate point on the surface and the scanning initiated. During operation the lightguide is stepped across the tissue surface point by point with a fixed distance to the tissue surface while the optical signals are recorded from each point, under computer control. The instrument allows for serial section scanning, which is carried out by milling away layers of tissue and repeating the scan on each new surface. Individual scans in a serial scan will be identical in size and shape, and will be vertically aligned. Such a data set may therefore be used for a 2- and 3-dimensional reconstruction of a "metabolic representation" of the sample, c.g., in terms of redox state, as shown below.

F1G. 1. Low-temperature redox ratio fluorometer. (a) The experimental laboratory model of the redox scanner; (b) a commercially available model. Components: (A) water-cooled mercury arc, (B) photomultiplier tubes, (C) rotating filter disks, (D) flexible lightguide, (E) drive and motor for low-temperature miller, (F) depth gauge for low-temperature milling, (G) liquid nitrogen inlet, (II) stepper motor-driven scanning stage (cf. Fig. 2), (l) low-temperature chamber, (J) computer and interface for fluorometer and stepper motors, (K) CRT display, and (L) mercury arc power supply. 
All information concerning the scan, i.e., scan size, step size, number of consecutive scans, and other experimental instructions, are entered into the computer at the start of the experiment. The entire experiment is then completed automatically according to these instructions. The scanning progresses at a speed of 5-10 points/s. Data may be retrieved at any time during or after the experiment for inspection or hard copy.

\section{Details on Construction and Operation of the Instrument}

The low-temperature milling system. The inside dimensions of the insulated scanning chamber are $20 \times 4 \times 5 \mathrm{~cm}$ and it contains about $250 \mathrm{ml}$ of liquid nitrogen, the level of which is kept constant by a feedback-regulated valve connected to a 200 -liter feeding Dewar (see Figs. 1 and 2). For most experiments, the nitrogen level in the scanning chamber is kept a few millimeters below the surface of the sample, since the signal-to-noise ratio decreases if the optical measurements are performed through liquid nitrogen. The sample is mounted in a holder which threads on a screw in the bottom of the chamber. A milling head, suited for low-temperature milling, protrudes through the lid of the chamber for grinding layers off the frozen sample. The milling head is a 16-bit angular cutter, diameter $40 \mathrm{~mm}$ (F. \& O. Tool Co. Inc., Three Rivers, Mass.). Between periods of milling, the milling head is being held in liquid nitrogen. Milling of the surface is performed by moving the whole scanning chamber relative to the milling head, (stage $X_{1} Z_{1}$, Fig. 2): First the scanning chamber is lowered in the $Z$ direction to the level at which the cut is going to be made. Then the cut is performed by moving the chamber in the $X$ direction against the rotating cutter. Any cut above a thickness of $10 \mu \mathrm{m}$ may be performed, but for cuts thicker than $200 \mu \mathrm{m}$ several passes of the miller must be used. One pass lasts about $30 \mathrm{~s}$. For discussion of details of the tissue milling process see (23).
Multichannel time-sharing microfluorometer. The fluorometer is a modified version of the time-sharing fluorometer described by Chance et al. (24). Figure 3 shows a block diagram of the instrument. It consists of two synchronized disks, rotating at $60 \mathrm{~Hz}$, which contain the optical filters. Each disk has four positions for filters, allowing simultaneous measurements of fluorescence and reflectance at four different wavelengths. A microlightguide of the one-end-fused two-branch type (25), forms the optical coupling between the fluorometer and the sample. The standard lightguide used with the instrument is made of quartz fibers with core diameters of 70 $\mu \mathrm{m}$, but fibers of $20-\mu \mathrm{m}$ core diameter have been employed with acceptable signal-to-noise ratio, provided repeated measurements were taken over each point. There are six fibers in the excitation branch, which in the fused end are arranged around a single central fiber, collecting the fluorescence emission or reflectance signals. The excitation fibers and the

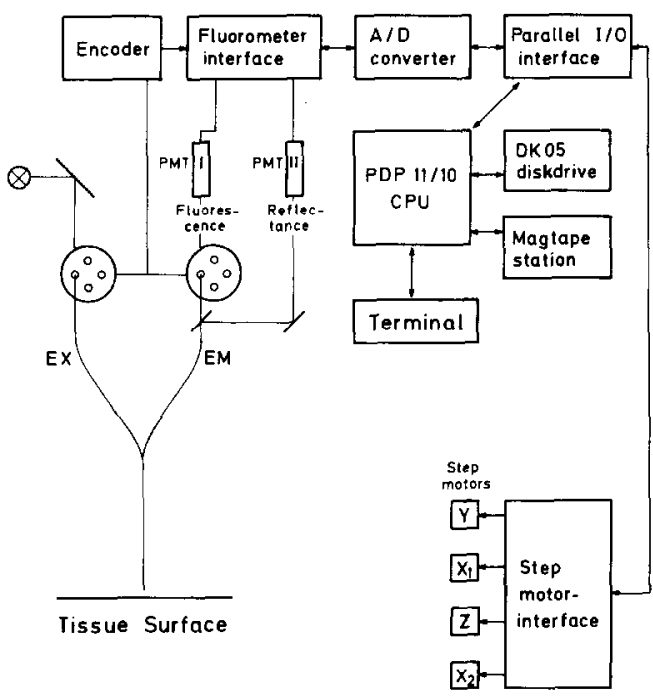

FiG. 3. Block diagram of the low-temperature scanner. The two rotating filter disks combined with two photomultipliers and a beam splitter in front of the secondary filters allow simultaneous measurements of fluorescence and reflectance at four different wavelengths. The stepper moturs denoted $Y, X_{1}, Z$, and $X_{2}$ refer to the directions of movement given in Fig. 2. 
emission fiber are enclosed in two $45-\mathrm{cm}-$ long flexible steel tubings, $0.6 \mathrm{~mm}$ o.d. The fused part is further enclosed in a $12-\mathrm{cm}$ long piece of rigid steel tubing, $3 \mathrm{~mm}$ o.d., clamped to the scanning cross-ways (see Fig. 2). (The lightguides were made in the Johnson Foundation workshop. Fibers were obtained from Shott Glasswerke, Wiesbaden, West Germany. Fibers were of the uv type, numerical aperture and half-opening angle varying with wavelength. At $366 \mathrm{~nm}$ the values are 0.23 and 27 , respectively.) $A$ beamsplitter $(95 \%$ transmission and $5 \%$ reflectance) allows simultaneous recording of fluorescence and reflectance (see Fig. 3).

The light source is a $100-\mathrm{W}$, short-mercury arc (Osram Corp., Berlin, West Germany) with an optical system focusing the image of the bright spot over the cathode of the arc on the excitation branch of the microlightguide. We have recently employed a $10-\mathrm{mW}$ helium-cadmium laser (Liconix Model 902, Liconix Inc., Calif.) in addition to the mercury arc, in order to get a more intense excitation of the FP fluorescence at $442 \mathrm{~nm}$. The two light beams are fused via a $1-\mathrm{mm}$ hole in a $45^{\circ}$ front-surface-silvered mirror.

For redox ratio measurements (see below) only two filter positions are used, i.e., for the measurement of pyridine nucleotide $(\mathrm{PN})^{1}$ and flavoprotein (FP) fluorescence. For PN the excitation wavelength is $366 \mathrm{~nm}$, obtained by a glass filter (Corning 5970 or Kodak Wratten 18A). For PN emission a filter combination giving peak transmission at $450 \mathrm{~nm}$ is used (Kodak Wratten gelatin filters 47B and 2E). For FP the corresponding values for excitation and emission are $436 \mathrm{~nm}$ (interference filter, hbw $20 \mathrm{~nm}$ ) and $520 \mathrm{~nm}$ (interference filter, hbw $10 \mathrm{~nm}$ ), respectively. (Interference filters were obtained from Acton Research Corp., Mass.). Reflectance signals are measured at the excitation wavelengths. The blocking of the secondary filters is suf-

\footnotetext{
${ }^{1}$ Abbreviations used: PN, pyridine nucleotide; FP, flavoprotein; SD, spreading depression.
}

ficient to exclude any reflectance signal from the tissue in the fluorescence channels.

Fluorometer and computer. The instrument may be used for any combination of $4 / 4$ channel fluorescence/reflectance measurements, depending on the filter combination used in the rotating filter disks. The fluorescence and reflectance signals are read by two separate photomultiplier tubes (EMI 9525B, EMI 9824B, or a side-detecting tube, $\mathrm{Ha}$ mamatsu R928). After current-to-voltage conversion and preamplification the analog signal from each of the two PM tubes is integrated in two separate 4-channel circuits (see Fig. 4). Signal integration, which is controlled by the filter-disk rotation encoder, takes place over four time intervals of approximately $1 \mathrm{~ms}$, corresponding to the passage of the four filters in front of the detector. The circuit provide for gain and offset of individual channels. This allows a calibration of the instrument on fluorescence and reflectance standards, ensuring, first, comparability between experiments and, second, that the fluorometer output in a given experiment will vary within the range $0-+5$ volts. The interface between the fluorometer and the computer is a 12-bit analog-to-digital converter operating at $240 \mathrm{kHz}$. Following the analog-to-digital conversion the data are read by the computer and, after an optional signal averaging, i.e., the lightguide may read the same point on the tissue surface a number of times before moving to the next point, data are stored on hard disk as sequential files, one file per scan. The computer is a Digital PDP 11/10 minicomputer, dedicated to the instrument, with 64 kbyte MOS memory, two RK05 disks, and a TE16 mag-tape station. The operating system is Digital RT11.

The signal intensity of each single-point measurement (fluorescence and/or reflectance) is stored as a single, unsigned 8-bit integer, giving a range of 256 different values for each pixel. A television image of a scan is thus composed of a number of pixels corresponding to the number of points 


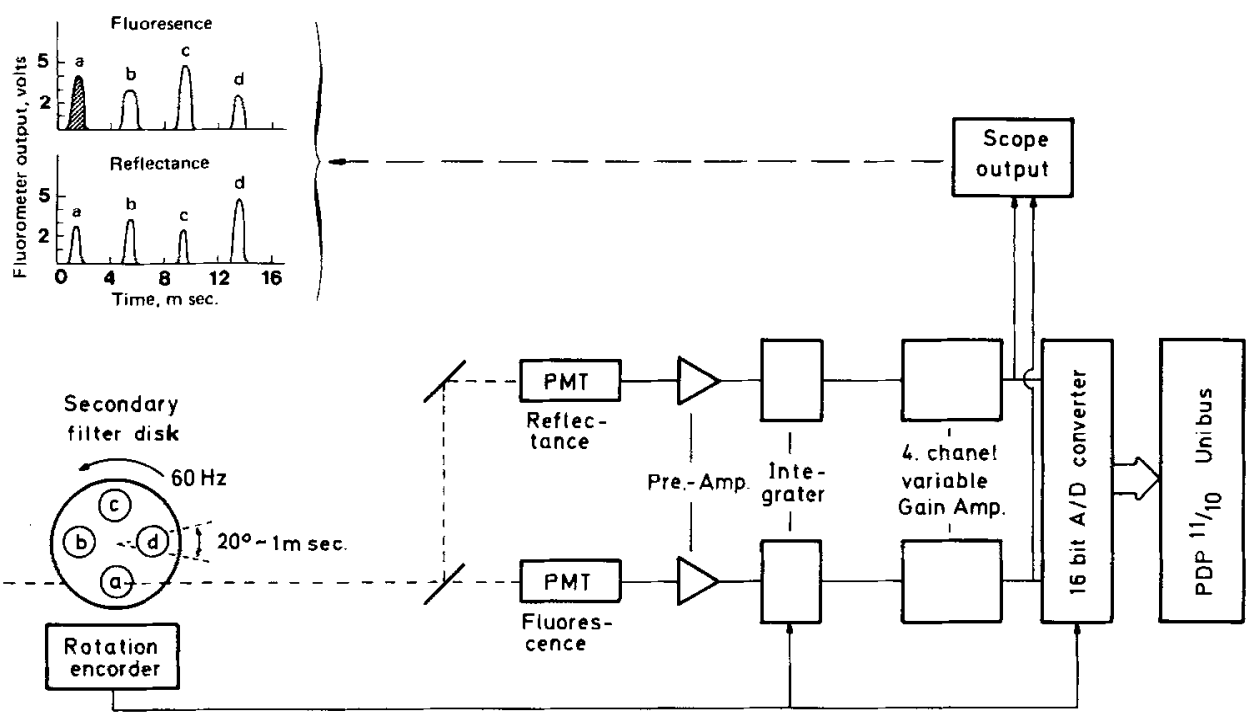

FIG. 4. Block diagram of fluorometer interface for the low-temperature scanner. Two parallel circuits integrate the fluorescence and reflectance signals in four 1-ms intervals-a, b, $c$, and $d$-defined by the rotation of the filter disk in front of the photomultiplier tubes. An example of signal output on the scope from the two photomultiplier tubes are shown in the upper left-hand part of the figure.

scanned on the particular tissue surface. Each point may be displayed with the appropriate shade of grey corresponding to the intensity of the point. We normally use a convention in which black represents a low number and white a high number. The data from successive slices are stored in a series of files on disk thus forming a data set containing a distribution of optical signals in three dimensions through the tissue. A typical example, representing scans from brain tissue, is explained below (Fig. 6).

The computer programs currently used with the instrument provide for the following data manipulations: (i) on-line scope-monitor display of any one of the parameters measured. A 2-D image of the scan may be recorded directly from the scope with a polaroid camera, with the fluorescence or reflectance signal modulating the intensity of the scope (Fig. 6A); (ii) matrix printout of raw data; (iii) frequency distribution histograms of individual scans of any of the parameters measured or of mathematical computations thereof (21); (iv) TV-monitor display of individual scans for any of the measured parameters or mathematical computations thereof. The TV picture allows for zooming and contrast manipulation (21); (v) a program which gives access to the data set as a whole, allowing the generation of a twodimensional distribution of signals across any plane cutting the block of tissue scanned, as exemplified for the rat heart (16).

\section{RESULTS AND DISCUSSION}

\section{Spatial Resolution of the Instrument}

The 2-D resolution in the scanning plane depends only upon the size and geometry of the lightguide (25). With a core diameter of the central collecting fiber of $70 \mu \mathrm{m}$ and a tissue-lightguide distance of $50 \mu \mathrm{m}$, which has been used in most experiments, the area covered on the surface is approximately 0.01 $\mathrm{mm}^{2}$. The resolution down through the tissue is, however, determined by other factors in addition to the geometry of the lightguide. Especially, the absorption in the tissue of the excitation light will strongly decrease the 
fluorescence, but also, the emitted fluorescence will be absorbed as it travels back up through the tissue to the collecting lightguide, resulting in an exponential loss of signal with depth. Furthermore, this internal filtering effect is wavelength dependent and may differ in different tissues (26). We have, however, developed an empirical method of deconvoluting the contribution of one scan to the one above it by scanning through the sample to a reference material, such as frozen buffer of uniform characteristics, and subtracting this from the immediately adjacent scan above it, obtaining thereby a "single layer data set" [(27); see also $(28,29)]$. We have up to the present time found few applications where this is necessary, but use of the principle identifies the 3-D resolution of the technique as a tissue cone defined by the opening angle of the lightguide, the lightguide core diameter, the tissue-lightguide distance, and the minimum cut thickness. With values for these parameters of $27^{\circ}$ and 20,30 , and $10 \mu \mathrm{m}$, respectively, the resolution is $2 \times 10^{-8}$ $\mathrm{ml}$, equivalent to a 20 -ng sample. In most tissues, however, a signal change of more than threefold is frequently observed in the same position in two consecutive scans separated by only $50 \mu \mathrm{m}$. Thus, for most applications this is taken as the effective pickup depth, i.e., the depth below which less than $10 \%$ of the signal originates. With the standard lightguide of a core diameter of $70 \mu \mathrm{m}$ this gives a spatial resolution of approximately $3 \times 10^{-7} \mathrm{ml}$.

The ischemic border zone in a model coronary occlusion on a rabbit heart (30) has been resolved spatially by redox scanning and compared with quantitative biochemical analysis of the NADH concentration in microsamples along the same line across the border zone between normoxic and anoxic tissue (20). This experiment demonstrates that the two contours, the PN fluorescence obtained by redox scanning and the chemically measured NADH, rise from 20 to $80 \%$ over a distance of $200 \mu \mathrm{m}$, and identify the same border zone between normoxic and anoxic tissue. It appears that both methods provide the resolution to precisely identify the zone of normoxia-anoxia transition in the model infarct. However, the application of higher resolution might have demonstrated an even steeper transition, as suggested by model simulation studies of tissue oxygen gradients (31).

\section{Freeze-quenching}

The aim of an experiment for which the low-temperature scanner is used is typically to obtain a 3-D analysis of metabolic state in relation to the anatomical structure of the tissue. The outline of the anoxic area of a model coronary occlusion $(16,18,30)$, the liver acinus (21) or the propagation of a spreading depression wave $[(15,50)$ and Fig. 6)], are typical examples. Freeze-quenching is a prerequisite in such studies since it stops metabolic processes, providing a "snap shot" of metabolism at the moment of freezing and also allowing a 3-D analysis by way of sectioning the frozen tissue block. Furthermore, fluorescence quantum yield is typically increased 5- to 10-fold at liquid nitrogen temperature, vastly improving the signal-to-noise ratio (32). Also, because of the complete arrest of metabolic processes, the time taken for the analysis is not of importance, which allows a high level of details as well as a high signal-to-noise ratio by signal averaging.

In order for the metabolic state in the frozen sample to reflect the in vivo state, the freeze-quenching procedure must be designed accordingly, i.e., to obtain the shortest possible time interval between interruption of normal circulation and quenching of metabolic processes. Even under optimal conditions, this implies that only small tissue samples or thin wafers of tissue can be used, since the freezing time in the tissue increases exponentially with distance from the cooled surface. Freezing, which is rapid enough to prevent that the sampling-and-quenching process per se contributes to the pattern of 
metabolic states observed in the frozen sample, could be termed "homogenous freezing." ${ }^{2}$ With slower freezing, however, the metabolic state will be affected to a different degree in different parts of the sample during freezing, "heterogenous freezing."

Typical scanning results with "homogenous freezing" are given in metabolic studies of rat liver (21). In other experiments, however, we have deliberately used "heterogenous freezing." Figure 5 shows an example of such an experiment in rat brain. The brain was freeze-clamped in vivo by a technique which applies precooled aluminium blocks on both sides of a 12-mm-wide slice cut through the brain, perpendicular to the length axis of the animal (33). The FP/PN ratio was scanned on 14 consecutive cross-sections of the brain between 50 and $3900 \mu \mathrm{m}$ below the surface of the frozen sample, with 144 data points per cross-section (8). The figure shows the average redox ratio of each cross-section. The ratio remains constant between 50 and 500 $\mu \mathrm{m}$. Then there is a rapid phase of reduction between 600 and $1900 \mu \mathrm{m}$ followed by a slow phase which may not be quite completed at $3900 \mu \mathrm{m}$.

Since the speed of progression of the freezing front has been experimentally determined for this particular freezing-clamping setup (34), it is possible to convert distances into actual time of ischemia, i.c., the time interval between interruption of blood supply by the sampling of the brain and arrest of metabolic processes by freezing. The quenching time for tissue in a depth of $960 \mu \mathrm{m}$ is about $1 \mathrm{~s}$ (34). Half reduction was reached at $1300 \mu \mathrm{m}$, corresponding to about $3 \mathrm{~s}$ of ischemia and $80 \%$ reduction after about $8 \mathrm{~s}$ of ischemia. In rat liver freeze-clamped in situ, similar

\footnotetext{
${ }^{2}$ It should be noted that the freeze-trapping of the type employed here will not preserve the in vivo state of the intracellular components with exact fidelity due to the growth of ice crystals in all but the most superficial cell layers. While this is a definite drawback for electron microscopy of tissues, it has not so far been a problem at the resolution of which we are presently capable.
}

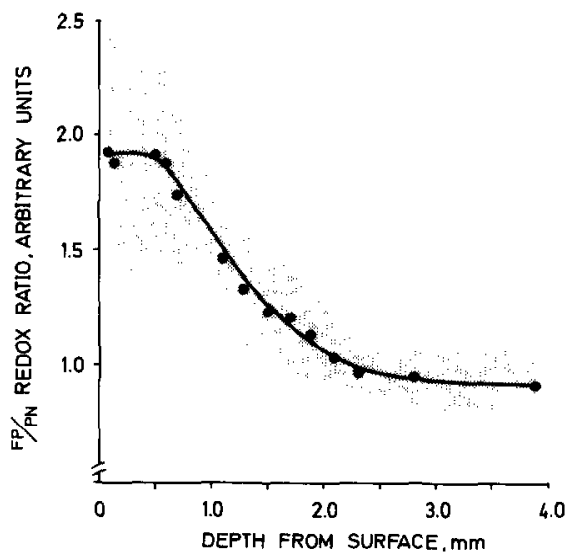

FIG. 5. Measurements of redox ratio in rat brain along the freezing gradient. A coronal slice of a rat brain, approximately $12 \mathrm{~mm}$ wide, was freeze-clamped and the FP/PN ratio was measured on 14 consecutive crosssections of the frozen sample between 50 and $3900 \mu \mathrm{m}$ from the surface. Lightguide core diameter was $70 \mu \mathrm{m}$ and step size was $500 \mu \mathrm{m}$, covering an area on the cross section of the brain of $36 \mathrm{~mm}^{2}$. The figures represent the average redox ratio of 144 redox ratio measurements on each scan.

experiments show only a $20 \%$ change in the chemically measured ATP/(ADP $\left.\times P_{\mathrm{i}}\right)$ ratio in a depth of 2.1-2.3 mm, corresponding to a quenching time of approximately $5-7 \mathrm{~s}$ (35). This difference between brain and liver probably reflects a difference both in terms of rate of oxygen consumption and in the amount of available oxygen stores in the two organs at the severance of blood circulation. The latter observations on liver agree with FP/PN ratio measurements on perfused livers, showing no changes in redox ratio distribution pattern within consecutive scans taken to a distance of $1 \mathrm{~mm}$ from the frozen surface $(17,21)$. As comparison half reduction of PN may be observed at an oxygen concentration of $8 \times 10^{-8} \mathrm{M}$ for a suspension of isolated pigeon heart mitochondria in state 3 (36).

\section{Fluorescence and Reflectance Parameters, the FP/PN Redox Ratio}

The parameters measured with this technique may include any intrinsic or added probe which lends itself to surface fluores- 
cence or surface reflectance measurements with a sufficient signal-to-noise ratio. So far the instrument has, however, mainly been used to measure the intrinsic fluochromes pyridine nucleotide (PN) and flavoprotein (FP). Measured as described above the PN signal is mainly NADH and NADPH while the FP signal originates from the flavine of the dehydrolipoamide dehydrogenase part of pyruvate dehydrogenase and $\alpha$-ketoglutarate dehydrogenase, which has by far the highest fluorescence yield among the various flavins (37-39). Chance and his collaborators first used these fluochromes as intrinsic redox indicators in intact tissue $[(40,48)$; for a recent review see $(7)]$. In the redox scanning instrument we have used the ratio of the flavoprotein fluorescence to pyridine nucleotide fluorescence (32). In isolated mitochondria this ratio is indeed a good indicator of the redox state since the flavoprotein is coupled to the mitochondrial NAD/NADH redox system by pyruvate dehydrogenase and $\alpha$ ketoglutarate dehydrogenase reactions (41). Furthermore, since only the reduced form of the PN system and the oxidized species of the FP couple is fluorescent, the ratio will indicate the redox state of the mitochondrial NAD/NADH redox couple. The FP/PN ratio (called CR, calculated ratio) can vary from 0.05 to 10 in isolated mitochondria (32). In intact tissue the redox span is much less, on the order of 2-3 (15-21). For computational convenience we have for some applications made use of a modified ratio, $\mathrm{MR}=\mathrm{FP} /(\mathrm{FP}$ $+\mathrm{PN})$, since this ratio always has a value in the range 0-1.0. As with the CR, a high MR means oxidized tissue and a low ratio means reduced. While the single fluorescence signals arc rather sensitive to changes in blood concentrations and the density of mitochondria, the ratio changes only slightly (32).

In intact tissue the use of the ratio as redox indicator may be difficult to interpret in terms of mitochondrial NAD/NADH redox state. While more than $90 \%$ of the flavin fluorescence is mitochondrial (42), the PN signal may originate from two different redox couples in two different compartments. The problem varies in different tissues. In brain, heart, and skeletal muscle, available data suggest that the PN signal predominantly originate from mitochondrial NADH (4346), while in the liver an almost equal contribution from the cytosolic and mitochondrial compartments to the PN signal was suggested (42). Recent results, however, suggest that the enhancement of roughly 10-fold of the NADH fluorescence that occurs on chilling the tissue to liquid nitrogen temperature applies to the bound NADH of the mitochondrial redox system. And the factor is much less for the NADH component of the cytosol, as determined by independent measurements of mitochondrial and cytosolic fractions of cells (B. Chance, unpublished observation).

When measuring PN fluorescence in rat brain cortex in vivo it was found necessary to correct the signal with simultaneously measured reflected infrared light (47). A satisfactory correction could be obtained by using the reflected PN excitation light at 366 $\mathrm{nm}$ (48). Reflectance corrections are usually not necessary with the redox scanner, due to the use of the ratio technique and because measurements are performed on frozen tissue. However, the reflectance signal may be useful for the generation of a "photographic image" of the scanned surface, applied, for example, in experiments with perfused liver to recognition of the lobular pattern (21).

\section{Example on 3-D Scanning}

One of the virtues of the redox ratioscanning technique is the ability to obtain information on 3-dimensional metabolic structure. Such data have been published for the model coronary occlusion (16) and the perfused rat liver (21). Figure 6 shows 3-D scanning data of a spreading depression (SD) wave in the cerebral cortex of a gerbil (15). The SD wave was elicited with a needle stab in the exposed parietal cortex and $45 \mathrm{~s}$ later 


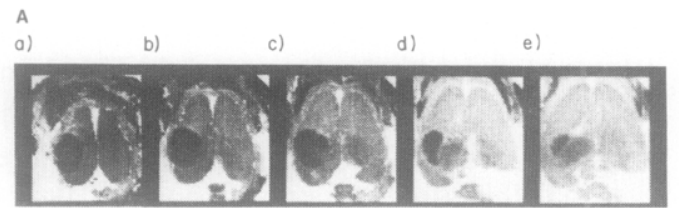

0.5

0.8

Depth Below Cortex (mm)



FIG. 6. Redox ratio scanning of a spreading depression wave in the cerebral cortex of gerbil brain. The anesthetized animal was craniotomized exposing the parietal and frontal cortex of the brain. Spreading depression (SD) was initiated by a needle stab in the left frontal cortex and the brain was frozen $45 \mathrm{~s}$ later by application of liquid nitrogen. (A) Five consecutive scans of the MR ratio recorded at different distances from the surface as indicated on the figure. The lightguide core diameter was $70 \mu \mathrm{m}$, step size was $200 \mu \mathrm{m}$, and the area covered in the individual scan was $12 \times 12 \mathrm{~mm}$. The redox span of the scans was $0.02-0.8$ for reduced and oxidized tissue, respectively. (B) A 3-D reconstruction of similar redox ratio data, where the SD wave was elicited in the right hemisphere. The MR ratio is given on an arbitrary scale where black is reduced and white oxidized.

the brain was frozen by application of liquid nitrogen. The scans were taken in longitudinal planes with $200-\mu \mathrm{m}$ step size and $200 \mu \mathrm{m}$ between individual scans. Fig. 6A shows redox ratio images of individual scans at different distances below the surface of the cortex, while Fig. 6B show a 3-D reconstruction of similar data with the SD elicited in the right hemispherc. A narrow band of oxidation (approx $0.5 \mathrm{~mm}$ wide) is seen at the propagation front of the wave (in particular, in Fig. 6A, panels b, c, and d). This band may correspond to the small decrease of blood flow, which has been shown to occur prior to the main blood flow increase and change in ion homeostasis in the SD wave $(49,50)$. The contralateral hemisphere often displays an accompanying SD wave, although of much less intensity, as is the case in the present experiment.

\section{CONCLUSION}

The instrument described in the present paper represents a significant advance in high resolution 3-D metabolic mapping. Imaging of any intrinsic or added probe in a frozen tissue sample is possible, provided the probe lends itself to surface fluorescence or reflectance measurements. Used in the redox ratioscanning mode the technique allows evaluation of intercellular redox gradients, providing a means of detecting zones of different metabolic activity of an organ, as exemplified by the 3-D mapping of a spreading depression wave in the brain, Fig. $6(15)$, or the identification of the "metabolic acinus" of the liver (21).

\section{ACKNOWLEDGMENT}

This research was supported in part by Grants USPHSAA-03517 and NINCDS-10939.

\section{REFERENCES}

1. Cori, C. F. (1956) in Currents in Biochemical Research (Green, D. E., ed.), pp. 198-214, Interscience, New York.

2. Katz, N., and Jungermann, K. (1975) Hoppe-Seyler's Z. Physiol. Chem. 35K, 244. 
3. Foltmann, B., Enevoldsen, B. S., Grunnet, N., and Quistorff, B. (eds.) (1979) Metabolic Control by Compartmentation: Inter- and Intracellular Heterogeneity in Mammalian Liver, Ninth Linderstrom-Lang Conference, Panum Institute, University of Copenhagen.

4. Sasse, D., Katz, N., and Jungermann, K. (1975) FEBS Lett. 57, 83-88.

5. Lowry, O. H., and Passonneau, J. V. (1972) A Flexible System of Enzymatic Analysis, Academic Press, New York.

6. Sokoloff, L., Reivich, M., Kennedy, C., Des Rosiers, M. H., Patlak, C. S., Pettigrew, K. D., Sakurada, O., and Shinohara, M. (1977) J. Neurochem. 28, 897-916.

7. Sies, H., and Brauser, B. (1979) in Methods of Biochemical Analysis (Glick, D., ed.), Vol. 26, pp. 285-325, Wiley, New York.

8. Quistorff, B., and Chance, B. (1977) in Oxygen and Physiological Function (Jöbsis, F. F., ed.), pp. 100-110, Professional Information Library, Dallas.

9. Ji, S., Lemasters, J. J., and Thurman, R. G. (1980) FEBS Lett. 113, 37-41.

10. Quistorff, B. (1983) in Isolation, Characterization, and Use of Hepatocytes (Harris, R. A., and Cornell, N. W., eds.), pp. 131-137, Elsevier, New York.

11. Häussinger, D. (1983). Eur. J. Biochem. 133, 269275.

12. Quistorff, B., Grunnet, N., and Cornell, N. W. (1985) Biochem. J. 226, 289-297.

13. Quistorff, B. (1985) Biochem. J., in press.

14. Haselgrove, J. C., Subramanian, V. H., Leigh, J. S., Jr., Gyulai, L., and Chance, B. (1983) Science (Washington, D. C.) 220, 1170-1173.

15. Haselgrove, J. C., Barlow, C. H., and Chance, B. (1980) in Cerebral Metabolism and Neuronal Function (Passonneau, J. V., Hawkins, R. A., Lust, W. D., and Welsh, F. A., eds.), pp. 72-76, Williams \& Wilkins, Baltimore.

16. Haselgrove, J. C., Barlow, C., Chance, B., Joyce, E., Kanamuller, H., and Bruckner, M. (1978) in Frontiers of Biological Energetics (Dutton, P. L., Leigh, J. S., and Scarpa, A., eds.), Vol. 2, pp. 1515-1522, Academic Press, New York.

17. Quistorff, B., Chance, B., and Takeda, H. (1978) in Frontiers of Biological Energetics (Dutton, P. L., Leigh, J. S., and Scarpa, A., eds.), Vol. 2, pp. 1487-1497, Academic Press, New York.

18. Chance, B., and Quistorff, B. (1978) in Oxygen Transport to Tissue (Silver, I. A., Erecinska, M., and Bicher, H. I., eds.), Vol. 3, pp. 331-338, Plenum, New York.

19. Shapiro, I. M., Golub, E. E., Kakuta, S., Haselgrove, J., Havery, J., Chance, B., and Frasca, P. (1982) Science (Washington, D. C.), 217, 950-952.

20. Chance, B., Barlow, C., Haselgrove, J. C., Nakase,
Y., Quistorff, B., Matschinsky, A., and Mayevsky, A. (1978) in Microenvironments and Metabolic Compartmentation (Srere, P. A., and Estabrook, R. W., eds.), pp. 131-148, Academic Press, New York.

21. Quistorff, B., and Chance, B. (1984) in Regulation of Hepatic Metabolism: Intra- and Intercellular Compartmentation (Thurman, R., Kauffman, F., and Jungermann, K., eds.), Plenum, New York, in press.

22. Chance, B., Barlow, C. H., Nakase, Y., Takeda, H., Mayevsky, A., Fischetti, R., Graham, N., and Sorge, J. (1978) Amer. J. Physiol. 235, H809H820.

23. Quistorff, B., and Chance, B. (1980) Anal. Biochem. 108, 237-248.

24. Chance, B., Legallais, V., Sorge, J., and Graham, N. (1975) Anal. Biochem. 66, 498-514.

25. Ji, S., Chance, B., Nishiki, K., Smith, T., and Rich, T. (1979) Amer. J. Physiol. 236, C144-C156.

26. Galeotti, T., van Rossum, D. V., Mayer, D. H., and Chance, B. (1970) Eur. J. Biochem. 17, 485-496.

27. Eleff, S., Quistorff, B., and Chance, B. (1976) Biomed. Eng. Soc. Meeting, Abstract F-46.

28. Cliffs, N. J. (1979) in Digital Image Processing (Castleman, K. R., ed.), pp. 351-360, PrenticeHall, Englewood Cliffs, N. J.

29. Weinstein, M., and Castleman, K. R. (1971) Proc. SPIE 26, 131-138.

30. Barlow, C. H., and Chance, B. (1976) Science (Washington, D. C.) 193, 909-910.

31. Quistorff, B., Hunding, A., and Chance, B. (1978) in Oxygen Transport to Tissue (Silver, I. A., Erecinska, M., and Bicher, I., eds.), Vol. 3, pp. 127-133, Plenum, New York.

32. Chance, B., Schoener, B., Oshino, R., Itschak, F., and Nakase, Y. (1979) J. Biol. Chem. 254, 47644771.

33. Quistorff, B. (1975) Anal. Biochem. 68, 102-118.

34. Quistorff, B. (1980) in Cerebral Metabolism and Neuronal Function (Passonneau, J. V., Hawkins, R. A., Lust, W. D., and Welsh, F. A., eds.), pp. 42-52, Williams \& Wilkins, Baltimore.

35. Quistorff, B., and Poulsen, H. (1980) Anal. Biochem. 108, 249-256.

36. Sugano, T., Oshino, N., and Chance, B. (1974) Biochem. Biophys. Acta 347, 340-358.

37. Chance, B., Williamson, J. R., Jamieson, D., and Schoener, B. (1965) Biochem. Z. 341, 357-377.

38. Chance, B., and Schoener, B. (1966) in Flavins and Flavoproteins (Slater, E. C., cd.), pp. 510-519, Elsevier, Amsterdam/New York.

39. Hassinen, I., and Chance, B. (1968) Biochem. Biophys. Res. Commun. 31, 895-900.

40. Chance, B., and Jöbsis, F. F. (1959) Nature (London) 4681, 195-197.

41. Chance, B., Mela, L., and Wong, D. (1968) in 
Flavins and Flavoproteins (Yagi, K., ed.), pp. 107-121, Univ. Park Press, Baltimore.

42. Scholz, R., Thurman, R. G., Williamson, J. R., Chance, B., and Bucher, Th. (1969) J. Biol. Chem. 244, 2317-2324.

43. Jöbsis, F. F., and Duffield, J. C. (1967) J. Gen. Physiol. 50, 1009-1047.

44. Chapman, J. B. (1972) J. Gen. Physiol. 59, 135154.

45. Williamson, J. R. (1965) J. Biol. Chem. 240, 23082318.

46. O’Connor, M. J., Welsh, F., Komarnicky, L., Davis,
T., Stevens, J., Lewis, D., and Herman, C. (1977) in Oxygen and Physiological Function (Jöbsis, F. F., ed.), pp. 90-99, Professional Information Library, Dallas.

47. Kobayashi, S. K., Nishiki, K., Kaede, K., and Ogata, E. (1971) J. Appl. Physiol. 31, 693-696.

48. Harbig, K., Chance, B., Kovach, A. G. B., and Reivich, M. (1976) J. Appl. Physiol. 41, 480-488.

49. Gjedde, A., Hansen, A. J., and Quistorff, B. (1981) $J$. Neurochem. 37, 807-812.

50. Hansen, A. J., Quistorff, B., and Gjedde, A. (1980) Acta Physiol. Scand. 109, 1-6. 